Old Dominion University ODU Digital Commons

2014

\title{
Developing Important Marine Mammal Area Criteria: Learning From Ecologically or Biologically Significant Areas and Key Biodiversity Areas
}

Collenn M. Corrigan

Jeff A. Ardron

Mia T. Comeros-Raynal

Old Dominion University

Erich Hoyt

Giuseppe Notarbartolo Di Sciara

See next page for additional authors

Follow this and additional works at: https://digitalcommons.odu.edu/biology_fac_pubs

Part of the Biodiversity Commons, Ecology and Evolutionary Biology Commons, Environmental $\underline{\text { Sciences Commons, and the Marine Biology Commons }}$

\section{Repository Citation}

Corrigan, Collenn M.; Ardron, Jeff A.; Comeros-Raynal, Mia T.; Hoyt, Erich; Di Sciara, Giuseppe Notarbartolo; and Carpenter, Kent E., "Developing Important Marine Mammal Area Criteria: Learning From Ecologically or Biologically Significant Areas and Key Biodiversity Areas" (2014). Biological Sciences Faculty Publications. 305.

https://digitalcommons.odu.edu/biology_fac_pubs/305

\section{Original Publication Citation}

Corrigan, C. M., Ardron, J. A., Comeros-Raynal, M. T., Hoyt, E., Di Sciara, G. N., \& Carpenter, K. E. (2014). Developing important marine mammal area criteria: Learning from ecologically or biologically significant areas and key biodiversity areas. Aquatic Conservation: Marine and Freshwater Ecosystems, 24((Suppl. 2)), 166-183. doi:10.1002/aqc.2513 
Authors

Collenn M. Corrigan, Jeff A. Ardron, Mia T. Comeros-Raynal, Erich Hoyt, Giuseppe Notarbartolo Di Sciara, and Kent E. Carpenter 


\title{
Developing important marine mammal area criteria: learning from ecologically or biologically significant areas and key biodiversity areas
}

\author{
COLLEEN M. CORRIGAN ${ }^{\mathrm{a}, *}$, JEFF A. ARDRON ${ }^{\mathrm{b}}$, MIA T. COMEROS-RAYNAL ${ }^{\mathrm{c}}$, ERICH HOYT $^{\mathrm{d}}$, \\ GIUSEPPE NOTARBARTOLO DI SCIARA ${ }^{\mathrm{e}}$ and KENT E. CARPENTER ${ }^{\mathrm{c}}$ \\ ${ }^{\mathrm{a}}$ University of Queensland, Brisbane, Australia \\ ${ }^{\mathrm{b}}$ Institute for Advanced Sustainability Studies (IASS), Berliner Strasse 130, Potsdam, Germany \\ ${ }^{\mathrm{c}}$ IUCN Global Species Programme/ Biological Sciences, Old Dominion University, Norfolk, Virginia, USA \\ ${ }^{\mathrm{d}}$ IUCN Marine Mammal Protected Areas Task Force/Whale and Dolphin Conservation, UK \\ ${ }^{\mathrm{e}}$ IUCN Marine Mammal Protected Areas Task Force/Tethys Research Institute, Milan, Italy
}

\begin{abstract}
1. This paper explores how criteria to identify important marine mammal areas (IMMAs) could be developed, and nested in existing global criteria. This process would consider 134 species of marine mammals.

2. Particular attention is given to two suites of global criteria to identify areas important for the persistence of marine biodiversity: Ecologically or Biologically Significant Areas (EBSAs) developed through the Convention on Biological Diversity (CBD), and Key Biodiversity Areas (KBAs) in revision through the International Union for the Conservation of Nature (IUCN). They are seen as mutually complementary in the development of IMMAs.

3. The specificities necessary for identifying important areas at scales below the global level may vary according to the region, the biophysical requirements of distinct populations, and available data. Refining and testing the applicability of these global criteria on marine mammals at both regional and national scales will be necessary.

4. Combining area-based measures with non-spatial management actions will likely be the optimal approach for ensuring marine mammal persistence given their highly migratory nature and widespread life-history stages.

5. Capacity to enact IMMAs is strengthened by the existence of professional marine mammal associations and networks, and the recently formed IUCN Marine Mammal Protected Areas Task Force (MMPATF). The MMPATF is planning further development of IMMA criteria through joint work with the International Committee on Marine Mammal Protected Areas (ICMMPA).

Copyright (C) 2014 John Wiley \& Sons, Ltd.
\end{abstract}

Received 9 April 2014; Revised 3 August 2014; Accepted 7 August 2014

KEY WORDS: key biodiversity areas; ecologically or biologically significant areas; marine mammals; protected areas; Aichi targets; convention on biological diversity; marine conservation

*Correspondence to: Colleen M. Corrigan, University of Queensland, Brisbane, Australia. E-mail: c.corrigan@uq.edu.au

This article forms part of the supplement 'Building Networks of MPAs: new insights from IMPAC3'. Publication of this supplement was supported by IUCN and WCPA with financial contributions from Parks Canada and United Nations Environment Programme (UNEP). 


\section{INTRODUCTION}

This paper explores how criteria to identify areas important for marine mammals can be developed, and how these criteria may nest within existing and emerging global classification systems. Two ongoing global processes with specific application in the marine environment are considered: (1) the identification of Ecologically or Biologically Significant Areas (EBSAs) as defined by seven site-based criteria adopted through the Convention on Biological Diversity (CBD, 2008); and (2) the ongoing refinement of criteria for Key Biodiversity Areas (KBAs) by the IUCN. The use of globally accepted criteria to identify areas that should receive attention for international as well as national protection has become accepted practice (Dearden and Topelko, 2005; CBD, 2008; Clark et al., 2014). However, given the diversity of life on land and in the oceans, there are inherent limits to how well these broad criteria systems can meet the needs of species and associated habitats at finer scales. Existing approaches are making important contributions in the protection of global biodiversity (Butchart et al., 2012); however, significant taxonomic and biogeographic gaps remain in the marine realm (Edgar and Brooks, 2011; Foster et al., 2012). Therefore, follow-on scientific processes to produce complementary species-specific criteria with increased detail and guidance are also needed.

To date 207 EBSAs have been described representing a total coverage of 265.7 million square kilometres. Of these, 47 areas have already been considered by CBD 11th Conference of Parties and submitted to the United Nations General Assembly (Rochette et al., 2014). The KBA methodology, which has been completely applied for multiple taxonomic groups in eight countries, and in progress for freshwater sites in more than 90 countries (Foster et al., 2012), has been applied in several marine regions: in the Philippines (Ambal et al., 2012), Galapagos (Edgar et al., 2008a), and Melanesia (Bass et al., 2011). The KBA criteria and their associated thresholds are currently under review and revision by IUCN's Species Survival Commission and the World Commission on Protected Areas.
In parallel with the work on KBAs, the IUCN Marine Mammal Protected Areas Task Force (MMPATF) was recently established to, inter alia, develop criteria for important marine mammal areas (IMMAs) as a complement to existing suites of criteria but with specific application for the conservation of marine mammals. The MMPATF hosted a workshop on this topic held concurrently with the Third International Marine Protected Areas Congress in Marseille, France, October 2013. Participants explored how criteria for IMMAs could build on experiences from other taxa-specific designations, such as Important Bird and Biodiversity Areas (IBAs), while still nesting within the global criteria systems noted above.

There is much to be learned from the IBA experience. To date, 12000 IBAs have been identified and documented worldwide by BirdLife International and partners (BirdLife International, 2014). The IBA experience informed the development of the first set of KBA criteria (Eken et al., 2004; Langhammer et al., 2007); as a result, the new IUCN standard being developed for KBAs incorporates and extends the IBA and similar approaches. IMMAs are expected to follow a similar model of integration.

In the development of IMMA criteria, consideration will need to be given to all marine mammal species as recognized by the IUCN Red List (Table 1). There are four main marine mammal groups: cetaceans, pinnipeds, sirenians and fissipeds (i.e. polar bears and otters). While not strictly marine in terms of habitat use, consideration will also be given to species that are found in freshwater environments (e.g. river dolphins and manatees) or which spend significant time on land (e.g. pinnipeds and fissipeds). To simplify the process, some representative species will initially be selected for testing. At the 2013 MMPATF workshop, it was considered how IMMAs could present a species-based sub-classification of EBSAs and/or KBAs, which have differences in intended applications (Marine Mammal Protected Areas Task Force, 2014) and are described further in this paper. As a designation of important features that may or may not require spatial protection, EBSAs are only loosely linked to marine protected areas (MPAs) (CBD, 2010), whereas KBAs were in part developed 
Table 1. IUCN Red List Categories for all known marine mammal species (IUCN Red List of Threatened Species website). EX - extinct, CR - critically endangered, EN - endangered, VU - vulnerable, NT - near threatened, LC - least concern, DD - data deficient

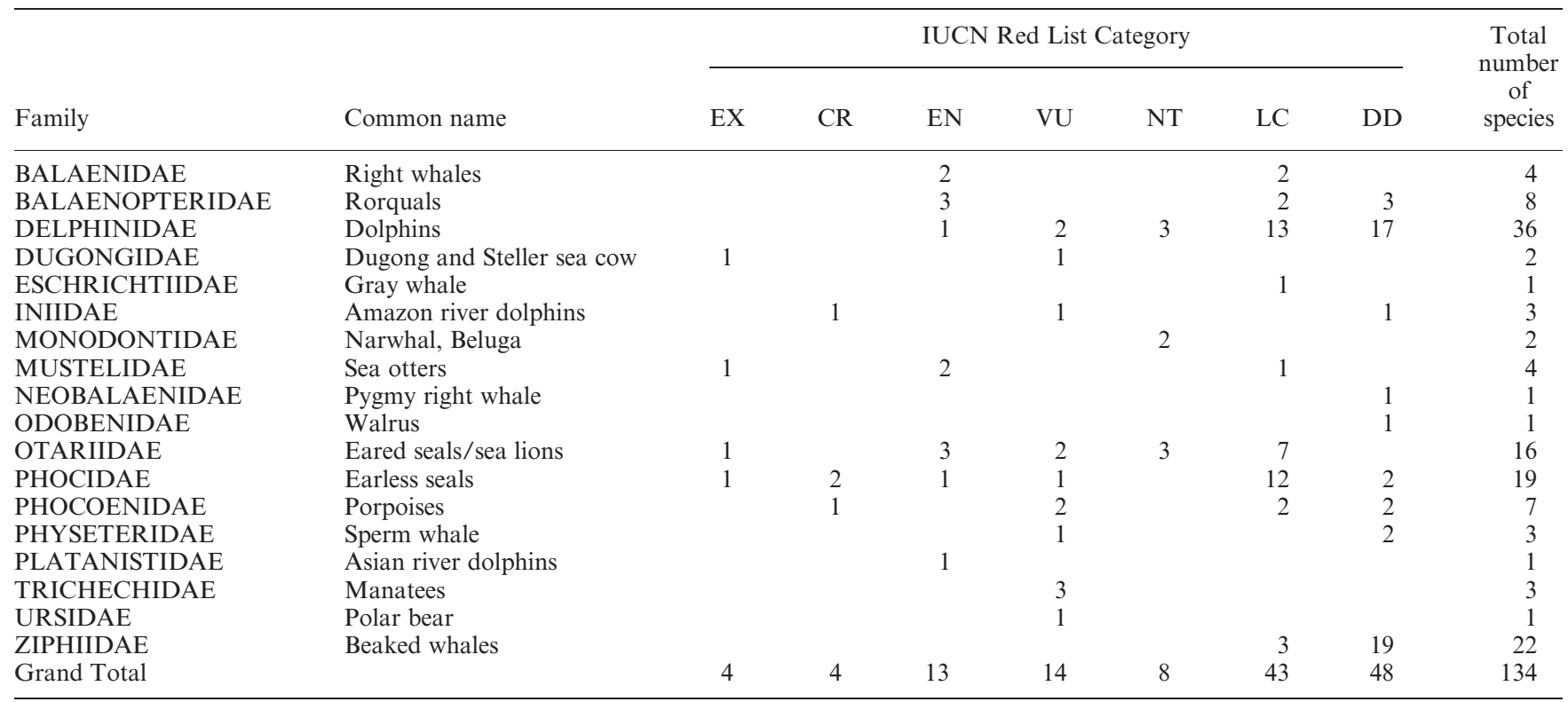

to guide the prioritization of conservation actions which may include protected areas (Langhammer et al., 2007). Participants of the 2013 workshop determined that IMMAs would be relevant to both EBSAs and KBAs via their separate processes (Marine Mammal Protected Areas Task Force, 2014).

\section{A focus on marine mammals}

Like birds, marine mammals have a number of characteristics making them suitable for a focal set of criteria. Comprising just over 130 species (Committee on Taxonomy, 2014), the limited number of marine mammals provides a useful focus for exploration. Marine mammals are, however, a highly diverse taxonomic group, occupying habitats on land, in freshwater and marine water environments, and include the largest living organisms on the planet. Such diversity will demand a broad range of management responses, as well as great flexibility within the IMMA criteria system.

These charismatic megafauna tend to be more data-rich than other marine species - an attribute that not only enables rigorous testing of criteria but also serves to increase public awareness of marine conservation issues and economic benefits (Hoyt, 2011; Farr et al., 2014; Marine Mammal
Protected Areas Task Force, 2014). In addition, protection of these species can also help support ecosystem-based conservation and its expansion in management applications, serve as indicators of ocean health and ecosystem degradation (Hoyt, 2011; Gomez-Salazara et al., 2012), and provide opportunities for regional collaboration (Hoyt, 2011), such as through the development of regional networks or transboundary sanctuary agreements for migratory species.

While the range of data available for marine mammals varies from species to species, as well as for populations of single species, there is likely enough information known about a core set of species to assess the appropriateness of global criteria and associated thresholds. For example, all marine mammal species, as well as an increasing number of geographic subpopulations, have been published on the IUCN Red List of Threatened Species. These extinction risk assessments contain species-specific information on distribution, population status, life-history parameters, and threats that can be used to inform appropriate spatially-explicit conservation actions. Humpback whales, for example, make a useful subject for the further analysis of IMMAs as they are well-studied around the world, including in the northern and southern hemispheres, and have 
multiple sanctuaries set aside specifically for protecting critical areas (McIntosh, 1999). Populations of humpback whales vary in their IUCN Red List categories, described further in this paper, enabling exploration of criteria that will allow these variations to be captured and better incorporated into management decisions. As studies and knowledge increase, it has become evident that some species-specific reserves do not adequately encompass their migration routes, as in the case of north Atlantic humpback whales (Kennedy et al., 2013), suggesting that identifying IMMAs can, inter alia, address existing spatial gaps for critical life stages of marine mammal species. However, identification of such places is only a first step, and a particular challenge of the IMMA process will be the necessary coordination of marine conservation efforts at regional and subregional scales that take into account the life-history requirements of species that traverse whole ocean basins.

Application and implementation of the site-based conservation approach, including that of EBSAs and KBAs, includes several challenges, such as how to protect taxa that are highly migratory and traversing international boundaries (Bass et al., 2011); scaling-up of individual EBSAs and KBAs to networks of managed areas (Langhammer et al., 2007; Foster et al., 2012; Dunn et al., 2014); widespread oceanographic threats that do not recognize national jurisdictions (e.g. climate change events); monitoring of identified sites; and general paucity of data for the marine system (Edgar et al., 2008b). Despite these challenges, actions are being undertaken for improved management and protection of the ocean. At a time of biodiversity decline and the rapid spread of anthropogenic impacts, however, there is a need to accomplish more, using the best-available scientific data to ensure persistence of populations and habitats of marine species and ecosystems. The eventual production and subsequent testing of IMMA criteria should provide useful insights for the further refinement and utility of global classification systems and enable a suitable baseline for comparison with other marine species and their respective management and conservation measures.
Developing criteria for IMMAs may also help address some of the concerns that have been raised regarding the emphasis on efficiency, where efforts to conserve the greatest number of species in the smallest space possible do not always result in comprehensive protection across the full range of biodiversity (Kareiva and Marvier, 2003). Given the diversity of habitats used and physical traits possessed by marine mammals, a key task in identifying IMMAs will be tallying the full range of data that exist, including what is known and unknown (Corrigan, 2013). In addition, the species-specific approach will need to be considered against what has already been learned through the holistic approach of systematic conservation planning and prioritization (Margules and Pressey, 2000; Pressey and Taffs, 2001).

The current trend of developing 'very large marine protected areas' as one strategy to enhance marine biodiversity protection may nonetheless fall short of meeting global conservation targets if critical management actions and key features that lead to conservation success are not understood and appropriately applied in protected area design (Agardy et al., 2011; Edgar et al., 2014). Although large size is frequently assumed to go hand in hand with marine mammal protection, depleted populations are dependent on a variety of management measures leading to population recovery and long-term protection (Lotze et al., 2011).

\section{Marine mammals in the IUCN Red List}

The 2008 Review of the IUCN Red List of Threatened Species included an assessment of the status of the world's 134 marine mammal species (Polidoro et al., 2008). Nearly 25\% of the marine mammals reviewed were listed as threatened (Figure 1), which suggests some urgency regarding the need to identify IMMAs, protected areas, or other actions that can support recovery or mitigate threats. A large portion of these species are listed as Data Deficient (36\%). Being 'Data Deficient' leads to uncertainty in estimating the true proportion of threatened species, because the extent to which these species are actually vulnerable to threats is not known (Bland et al., 2012; Morais et al., 2013). For further development of IMMA criteria, and 


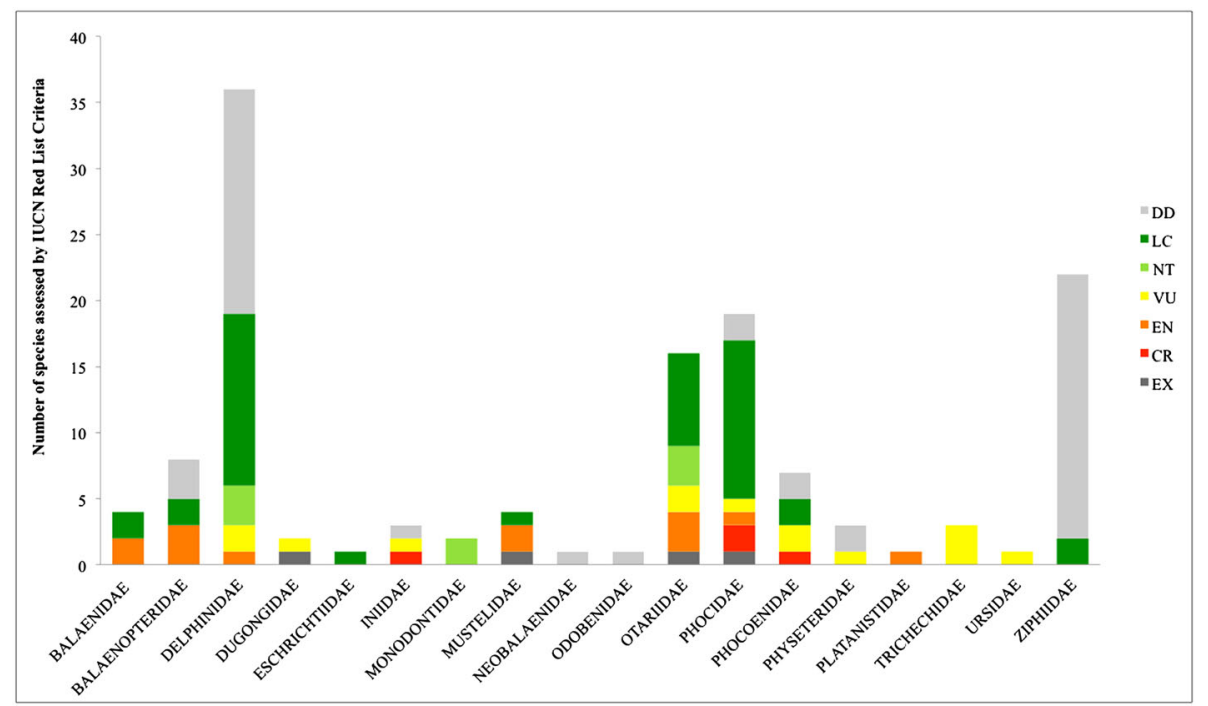

Figure 1. Categories of marine mammal family classifications as published on the IUCN Red List of Threatened Species.

their implementation, it will be necessary to differentiate between those marine mammals for which there is comparatively greater availability of data, and those that lack the information to adequately quantify the impacts of known threats to the populations. It will also be important to note the regional variation of biophysical and species data. Threats are discussed later in this paper.

Table 1 and Figure 1 demonstrate the variation in IUCN Red List categories of marine mammal species according to family groups. Nineteen of 22 species of beaked whales (Family Ziphiidae) are listed as Data Deficient, and the remaining three species are of Least Concern. The other notable group with insufficient data for listing includes the dolphins (Family Delphinidae), where nearly $50 \%$ (17 out of 36 ) of species are Data Deficient. These two groups thus warrant further research. The three species of Amazon River dolphins (Family Iniidae) are listed as Critically Endangered, Vulnerable, and Data Deficient, indicating attention to this group is also important. Two-thirds of sea otters (Family Mustelidae) are Endangered, as are two of the four right whale species (Family Balaenidae). Red List status is informed by intrinsic and extrinsic threats, thus understanding the life-history traits and vulnerability to threats faced by different families within the marine mammal clade should help inform the development of IMMA criteria and subsequently the utility of IMMAs.
To ensure persistence of subspecies and distinct populations, the application of IMMA criteria will need to take into account the variations of subpopulations within single species of marine mammals. Table 2 shows the different categories assigned in IUCN Red Listing for humpback whales (Megaptera novaeangliae) and bottlenose dolphins (Tursiops truncatus), two of the more commonly studied marine mammal species. While both species are globally assessed as Least Concern, both have subpopulations listed in elevated extinction risk categories (as Vulnerable, Endangered, and even Critically Endangered). Depending on how global criteria such as that for EBSAs and KBAs are applied, and at what scale, careful attention will be required to ensure these critical subpopulations are not overlooked. It is noted that the broadening of KBA criterion A from threatened species to threatened taxa should help facilitate inclusion of IMMAs.

\section{Examples of national processes to identify areas important to marine mammals}

A map of important areas for humpback whale populations in Australia (Figure 2) illustrates an ongoing national assessment. Coined 'Biologically Important Areas' (BIAs), they have been mapped separately for different marine mammal and other species (Brettell, 2013). Recovery plans for the 
Australian populations of humpback whale outline the key identified threats and other potential threats that could affect this species, and include actions that could be used to abate threats and promote recovery, including protection of critical habitat (Department of the Environment and Heritage, 2005). For example, identified threats in Australia include resumption of commercial whaling and/or the expansion of scientific whaling, natural predation on calves, and anthropogenic impacts resulting in habitat degradation (Australia Government Department of Environment, 2014). Potential threats include those associated with the impacts of climate and oceanographic change on habitat and food availability as well as impacts from overfishing of prey. As a means of advancing IMMAs, it could be useful to assess the spatial relationship of these different threats to distinct species populations around the coast of Australia.

The United States has also been identifying areas important for cetaceans through the Biologically Important Areas (BIA) component of the Cetacean and Sound Mapping (CetMap) project (CetMap, 2014). The purpose of this work is to complement quantitative density and distribution maps by identifying areas where it is known that cetaceans (populations or species) are congregating for various behavioural reasons or because of range limitations. Written documentation, accompanying maps, and metadata are required for the descriptions of BIAs, allowing public review that can help ensure the best available science and expert input has been used. In CetMap, modelling has been used to improve understanding of cetacean density and distribution in the US Exclusive Economic Zone. This approach, which allows for inclusion of areas where data may be limited, can provide additional understanding of potential human/cetacean interactions. While this work has been focused on cetaceans, the methods can be applied to other marine mammals.

Threats have not been explicitly overlaid with the above important biological areas, but generating such a layer could assist with prioritization and consideration of which actions would be implemented for protection. In the case of highly mobile marine species, place-based conservation mechanisms such as protected areas is just one of a suite of suitable options. Subsequently matching the locations of key life-history stages, as identified in an IMMA process, with key threats allows for the provision of protection via threat abatement, which goes beyond the establishment of boundaries on a map, and can help address threats to marine mammals in an integrated and proactive approach.

\section{Global criteria suites}

Criteria used to identify important spatial areas for the safeguarding of biodiversity have been developed and applied by the conservation community and governments for some time. Criteria can be applied to protect single species or a combination of species. Each criteria system comes with its own underlying set of assumptions concerning application. World Heritage Areas, for example, rely upon separate sets of natural and cultural criteria to identify areas of 'Outstanding Universal Value' (World Heritage Center, 1975). While global in scope, the World Heritage Convention has not, to date, been applied in marine areas beyond national jurisdiction (ABNJ). Some criteria systems apply only to specific taxa

Table 2. Sub-global Red List assessments of the humpback whale (Megaptera novaeangliae) and bottlenose dolphin (Tursiops truncatus). For categories see Table 1

\begin{tabular}{lllll}
\hline Family & Genus & Species & Subpopulation & IUCN Red List Category \\
\hline BALAENOPTERIDAE & Megaptera & novaeangliae & & LC \\
BALAENOPTERIDAE & Megaptera & novaeangliae & Oceania subpopulation & EN \\
BALAENOPTERIDAE & Megaptera & novaeangliae & Arabian Sea subpopulation & EN \\
DELPHINIDAE & Tursiops & truncatus & Fjordland subpopulation & CR \\
DELPHINIDAE & Tursiops & truncatus & Mediterranean subpopulation & VU \\
DELPHINIDAE & Tursiops & truncatus & & LC \\
DELPHINIDAE & Tursiops & truncatus & Tursiops truncatus ssp. ponticus & EN \\
\hline
\end{tabular}


Case Study: Humpback whales (Megaptera noveangliae) in Australia

The Australia Government's Department of Environment identifies Biologically Important Areas (BIAs) at the national level using species listed under the 1999 Environment Protection and Biodiversity Conservation Act and based upon expert scientific knowledge about species' distribution, abundance and behaviour. The selection of species is informed by the availability of scientific information, conservation status and importance of the region for the species. As new information becomes available, the BIAs are amended (Brettell, 2013).

Important areas for humpback whales have been identified, and include categories specific to where breeding, calving, foraging, resting, and migration occur.

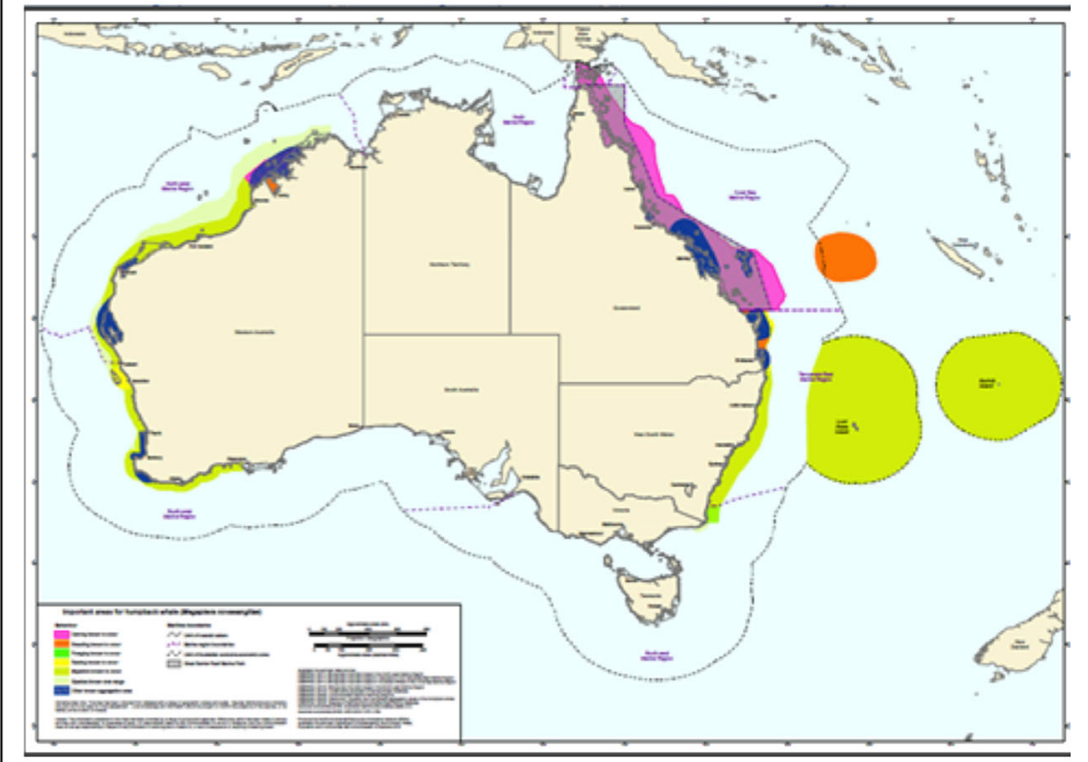

Important areas for humpback whale (Megaptera novaeangliae)

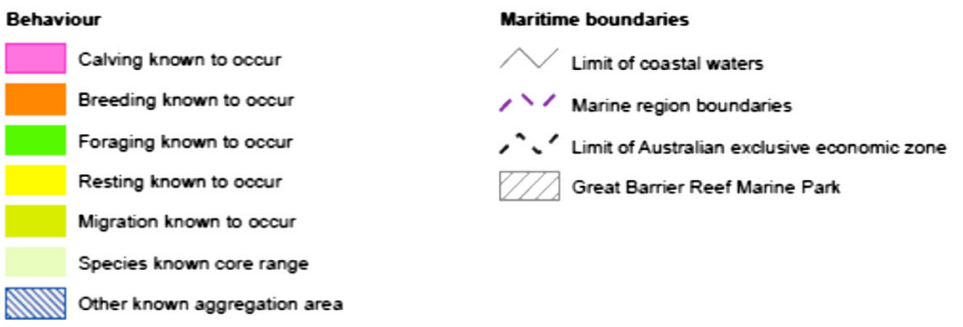

Indicative Map Only. This map nas been complled from datasets with a range of geographic scales and qualty. Spedes distributions are indicative

Figure 2. Biologically Important Areas for humpback whales (Megaptera novaeangliae) in Australia.

or habitat types, such as the IBAs discussed above, while others focus on a specific habitat type or ecosystem (e.g. the Criteria for Identifying Wetlands of International Importance; Ramsar, 1999). They can be adapted to identify important areas at the global scale as well as regionally and nationally; for example, BirdLife International has more than 100 national and regional inventories (BirdLife International, 2014).

Criteria are used in the first instance to identify areas that meet a certain threshold; they can then be utilized as a data layer in subsequent conservation planning to help make decisions about which areas should receive priority for 
protection, and through which management intervention. Within the marine context, some sets of criteria have been designed with sector-specific activities in mind; e.g. 'Vulnerable Marine Ecosystems' (VMEs) in the context of bottom fisheries in the high seas (Food and Agriculture Organization of the United Nations, 2009), or 'Particularly Sensitive Sea Areas' (PSSAs) in the context of shipping (International Maritime Organization, 2005). Often the criteria are quite broad and diverse, and of these, the CBD's EBSA criteria are arguably the broadest, with some described EBSAs containing oceanic sub-basins as large as the Amazon rain forest (Dunn et al., 2014). It has been argued that identifying broad-scale areas allows for a suite of management measures to be applied within them (Weaver and Johnson, 2012). However, management actions that are feasible for these vast scales are limited and would not, presumably, include stringent MPAs.

\section{Ecologically or Biologically Significant Areas}

Ecologically or Biologically Significant Areas were initially a response to the call to address marine biodiversity in the 'open ocean and deep sea' which largely falls outside the limits of national jurisdiction (Ardron et al., 2009). In 2006, an expert meeting of the CBD was held to review criteria that could be used for identifying EBSAs, which were clearly de-linked from MPAs. Table 3 is taken from the background paper drafted for that expert meeting (Dearden and Topelko, 2005; references from Table 3 are found in the original paper). The table, slightly modified and republished by the CBD (2005), lists 27 consolidated criteria as derived from a review of 20 sources or classification systems developed to identify candidate sites for MPAs. Using insights and lessons learnt from the application of these different sets of criteria, over the course of subsequent meetings with experts and negotiations at CBD Conferences of Parties, these multiple sets of criteria were reviewed and revised into the existing set of seven EBSA site criteria. These include (adapted from CBD, 2008, Annex I):
1. Uniqueness or rarity

2. Special importance for life history of species

3. Importance for threatened, endangered or declining species and/or habitats

4. Vulnerability, fragility, sensitivity, slow recovery

5. Biological productivity

6. Biological diversity

7. Naturalness

The extent of the various criteria systems feeding into the EBSA process speaks to the breadth of the criteria that emerged to guide the identification of these marine areas in need of enhanced protection, though not exclusively spatial protection (CBD, 2010). The EBSA criteria, as well as criteria to guide the development of MPA networks, were adopted at the 9th CBD Conference of Parties in 2008 (CBD, 2008, Annexes I and II). The EBSA approach has been expanded beyond its original intent and is now also used to support the identification of areas within national jurisdiction, thus enabling developing countries to utilize the process to help achieve CBD National Biodiversity Strategies and Action Plans; report progress on the 'Aichi Targets' (particularly Target 11, regarding protected areas); reinforce and promote the status of national protected areas; and provide access to international funding for site-based conservation and spatial conservation planning initiatives (Dunn et al., 2014). There has been a number of significant milestones in the identification of EBSAs around the world through regional workshops organized by the CBD Secretariat and attended by State nominated experts. However, challenges remain in the timely dissemination of information and results to CBD Parties, the repeatability of the expert workshop approach, and whether management considerations in these identified sites will be taken up by other global, but sector-specific, classifications (e.g. PSSAs regarding shipping, VMEs regarding bottom fisheries, and Areas of Particular Environmental Interest (APEIs) concerning mining) (Clark et al., 2014; Dunn et al., 2014). Regardless, the transdisciplinary insights and goodwill gained from this process to date have been invaluable, and the ongoing identification of EBSAs provides an ideal basis upon which to consider IMMAs. 


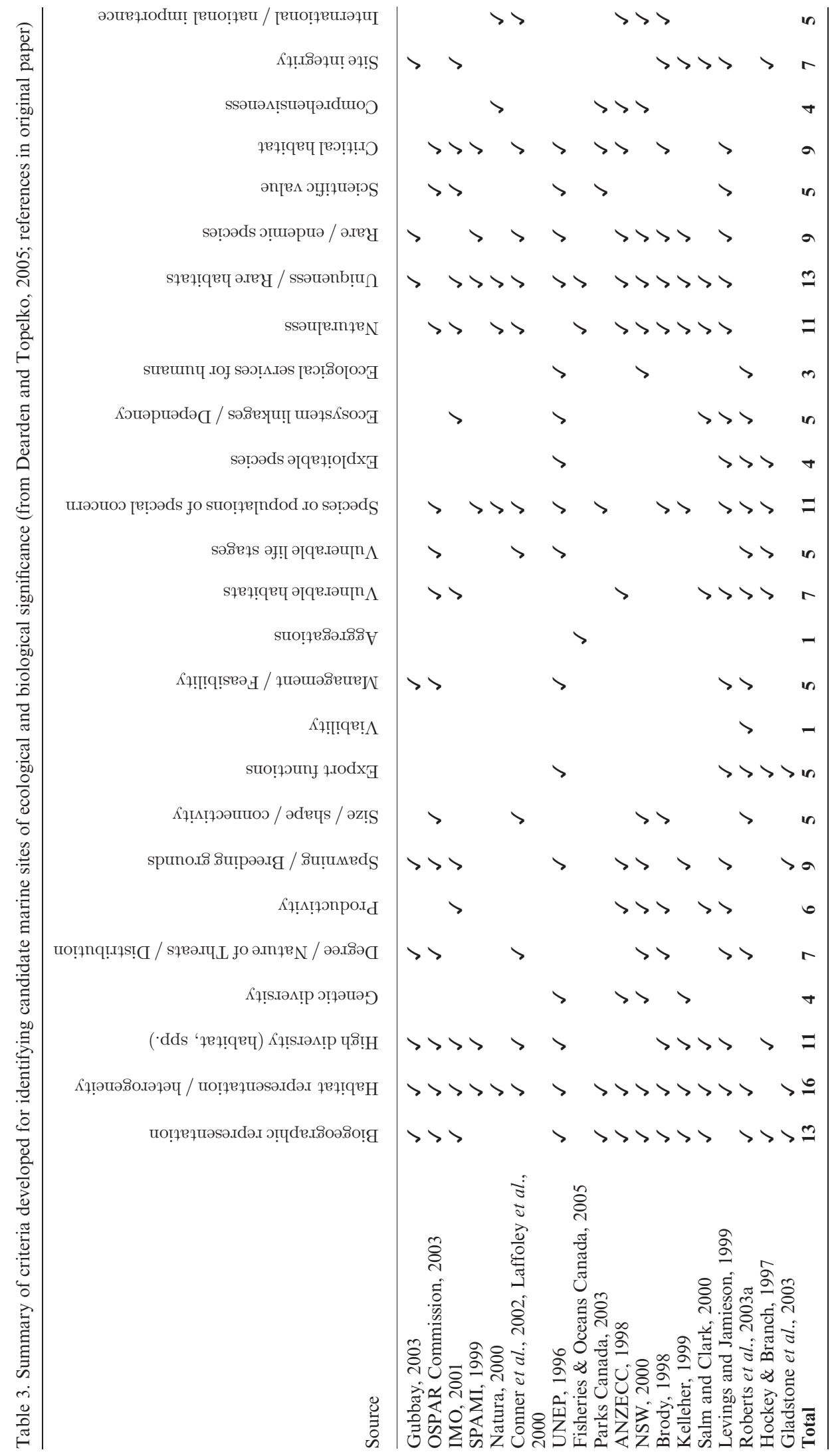


In summary, EBSAs demonstrate the following strengths and limitations:

Strengths.

- The seven EBSA criteria were derived from a wide range of criteria developed specifically for application in the marine environment. Thus, EBSA criteria have included from the outset some of the specific issues associated with conservation in the marine realm.

- EBSA criteria were sourced from other marine-specific suites of criteria used at the global level (such as Particularly Sensitive Sea Areas), regional level (such as Specially Protected Areas of Mediterranean Interest), the national level (e.g. nationally important marine nature conservation features and areas in the UK), and sub-national level (e.g. Australia's nine criteria used for identifying MPAs in New South Wales; criteria used for a network of MPAs in the Gulf of Maine).

- The source classification systems from which EBSA criteria were derived had already been reviewed and agreed upon by numerous experts, organizations, and government agencies.

- EBSA criteria are sufficiently broad to provide a suitably flexible basis allowing for the identification of marine habitats and ecological processes that underpin the health and viability of a wide range of marine taxa, including marine mammal species and their populations.

- EBSA criteria have been adopted at the international level by Parties to the CBD, a global treaty with near-universal acceptance (194 parties), which is critical for political acceptance of their use nationally, regionally, and internationally.

\section{Limitations.}

- Like any broad classification system, the lack of EBSA specificity requires further refinement for their application in the case of specific taxa; e.g. identifying IMMAs.

- Thresholds for the EBSA criteria do not exist. While this circumvents the data-driven requirements of KBAs, in the qualitative ranking approach used for EBSAs, meeting one criterion is sufficient for a site to be described as an EBSA. In practice, this has meant that a mix of very large areas, as well as moderate- and small-sized sites, has been described.

- The requirement for EBSAs to be endorsed by Parties to the CBD means the process can be slow; however, this is at the same time a strength in terms of political acceptance once the process is completed.

\section{Key Biodiversity Areas}

While EBSAs fall within the realm of the CBD, Key Biodiversity Areas (KBAs) are overseen through a process managed by the IUCN where the criteria are currently undergoing revision. KBAs are sites deemed to contribute significantly to the global persistence of biodiversity and are identified using globally standardized criteria and thresholds (IUCN, 2012). The KBA methodology builds on the experience of identification, protection, and monitoring of Important Bird and Biodiversity Areas (IBAs) conducted over the past three decades by the BirdLife International partnership (Eken et al., 2004; Langhammer et al., 2007; Foster et al., 2012; BirdLife International, 2014). The IBA approach has been extended to include other taxa: Important Plant Areas (IPAs) (Anderson, 2002; Plantlife International, 2004), Prime Butterfly Areas (van Swaay and Warren, 2003), Important Freshwater Biodiversity Areas (Darwall and Vie, 2005; Holland et al., 2012), and of particular relevance to this paper, Important Mammal Areas (Linzey, 2002). To date, KBAs have been extensively applied on land and in freshwater systems across a suite of taxa and biomes in more than 80 countries with another 73 partially complete or in progress; as a result, there is much to be learned from their application.

The IUCN Joint Task Force on Biodiversity and Protected Areas was created in 2009 to incorporate scientific stakeholder consensus to a new globally-agreed standard that builds on previous site-identification efforts (IBAs, IPAs, etc.). As part of the Task Force's objective to continue to consolidate the KBA criteria, a number of consultation workshops have been conducted since 2012 to develop new criteria and thresholds that can be globally and consistently applied across taxa, ecosystems, and ecoregions. The five criteria proposed under the new KBA standard (IUCN, 2013) aim to identify sites that contribute significantly to the global persistence of:

A. Threatened biodiversity

B. Geographically restricted biodiversity

C. Exceptional ecological integrity and naturalness

D. Critical ecological processes 
E. Biodiversity as identified through a comprehensive quantitative analysis of irreplaceability

The new IUCN standard for KBAs, including detailed description and rationale for the criteria and quantitative thresholds, will be launched in 2014. A central aim in this process of refining the KBA approach is to ensure that the methodology is pragmatic for conservation practitioners, stakeholders, and end-users while also remaining scientifically rigorous. Testing the criteria and thresholds for marine mammals through the development of IMMAs is seen as a component of the evolving KBA methodology (Langhammer, pers. comm.).

The new KBA criteria of particular relevance for marine mammals include (A) threatened biodiversity and (D) critical ecological processes. Criterion A includes both threatened taxa and ecosystems. Hence, taxa (both species and subspecies) assessed as globally threatened (CR, $\mathrm{EN}$, or VU) on the IUCN Red List that occur at a site at threshold numbers would trigger KBA status. Criterion D includes demographic aggregations and source populations. Sites where species aggregate in globally significant numbers during key life-history events, such as breeding, spawning, and feeding during migration, would qualify as KBAs.

Using previous KBA iterations, provisional criteria and thresholds for a number of species including marine mammals were identified in the Eastern Tropical Pacific (Edgar et al., 2008a), Melanesia (Bass et al., 2011), and the Philippines (Ambal et al., 2012). Bass et al. (2011) highlighted certain adjustments to the thresholds that allow for appropriate application for widely distributed marine species and provided a framework in the use of the thresholds wherein different sources and types of data may potentially lead to inaccuracies of population estimates. For example, using all records of threatened sea turtles (Critically Endangered and Endangered) in Micronesia resulted in an excessive number of KBAs, however, refining the thresholds to number of breeding females and a threshold of $1 \%$ of a genetic stock aggregating at a site resulted in sites that are more appropriate for prioritization processes.
Previous iterations of the KBA criteria (Langhammer et al., 2007; Edgar et al., 2008b) have included threatened species and globally significant congregations. These criteria and their associated thresholds were applied extensively to terrestrial and freshwater systems (Langhammer et al., 2007), but they required further testing for the marine realm to account for the substantial differences that exist between marine and terrestrial environments; for example, larger size and three-dimensional nature of marine habitats, higher connectivity, a wider range of turnover rates, and more extensive species ranges. There is now a need to test the new proposed KBA thresholds for marine mammals (and other marine taxa), especially under criteria $\mathrm{A}$ and $\mathrm{D}$, to ensure that they are practical and reasonable. A key concern is whether the thresholds will result in an appropriate number of sites identified (i.e. not being too lenient or too severe). Rather than using absolute thresholds for number of individuals occurring at a site, the new KBA thresholds for threatened biodiversity will be relative to the total population of the species. For example, a site must have at least $\mathrm{X} \%$ of the global population of a taxon plus a threshold number of functional reproductive units (to avoid trivial or non-viable sites). The thresholds proposed under criterion $\mathrm{D}$ will remain as $\mathrm{X} \%$ of the global population at the site (Edgar et al., 2008b), but they still require testing for their practicality and biological relevance.

Constraining the identification of marine KBAs to date has been availability of data on the distribution of, and threats to, taxa (Edgar et al., 2008b); and information on key life-history characteristics (e.g. formation of spawning aggregations). The IUCN Red List of Threatened Species provides species-specific information on relative extinction risk in the near future given intrinsic and extrinsic attributes (IUCN, 2001). The information generated from Red List assessments can be used not only to inform the identification of KBAs, but can also facilitate effective marine testing of the new KBA thresholds and criteria (Edgar et al., 2008b; Edgar and Brooks, 2011). An appropriate suite of taxa 
assessed under IUCN Red List Criteria now exists to help test new KBA methodologies for the Eastern Tropical Pacific Ocean (Polidoro et al., 2012), and the Mediterranean (Reeves and Notarbartolo di Sciara, 2006; Abdul Malak et al., 2011), and will soon be available for other areas as well (Dulvy, 2013). Thus, the use of this updated data can be explored for IMMAs as a means to test the KBA criteria.

In summary, KBAs come with certain strengths and opportunities for refinement:

\section{Strengths.}

- KBAs have been used and applied for a number of years by international conservation organizations and partners to identify important areas of biodiversity on land and in freshwater.

- KBA criteria and thresholds have been explored across some marine species groups and for specific taxa. This has provided valuable lessons and demonstrations on how to adjust and modify thresholds. Guidelines exist for the use of KBA criteria, and adapting these for use in IMMAs is plausible.

- KBAs do not rely on government-led consensus-driven decision-making processes, and thus can be identified and confirmed relatively quickly.

\section{Limitations.}

- KBA application in the marine realm has to date been limited.

- KBA criteria are designed to be applicable to all taxonomic groups and biomes. It is unclear whether the KBA criteria are adequately comprehensive for marine mammals, i.e. whether there are some types of sites important to the global persistence of marine mammals that would not be identified under the suite of KBA criteria.

- National or regional guidance has not yet been provided even though this is where conservation management decisions are made and actions, such as monitoring and enforcement, are undertaken.

- Marine KBA thresholds have not yet been finalized or tested specifically for marine mammal taxa; however, a process is underway. A challenge is meeting the data requirements for setting and assessing such thresholds.

- No formal review or revision process has been initiated based on field tests in the marine environment and field practitioners have received little guidance on how to modify the thresholds. Further work is required.

\section{CONSIDERATIONS FOR IMPORTANT MARINE MAMMAL AREAS}

Determining the criteria for IMMAs should be an iterative process of exploring criteria and, when appropriate, associated thresholds which are flexible to suit subpopulations and geographic variations. A Working Group formed at the 2013 MMPATF workshop suggested the following as a starting point for considering IMMA criteria:

- Reproductive areas and times

- Feeding areas and times

- Migration corridors

- Smaller or resident populations

- Abundance estimates and population structure (with consideration of rarity, uniqueness, genetic isolation, irreplaceability, size of populations, and temporal aggregations)

- 3-D habitat features

- Considerations of vulnerability and resilience

These draft considerations offer a foundation for further development that, when coupled with a process informed by EBSAs and KBAs, should allow for nesting IMMAs within global criteria and their identified sites. However, while IMMAs might prima facie fit the EBSA criteria, the adoption and implementation of this listing may take some time since EBSAs require inter-governmental acceptance.

As discussed at the 2013 MMPATF workshop, in order to move forward on the agreement of IMMA criteria, it would be advantageous to conduct trials on single and multiple groups of species across the four main marine mammal groups, across different biogeographic regions (the classification of which can remain to be determined), and across the IUCN Red List categories. Though some redundancy in criteria/thresholds among marine mammal species is inevitable, it will nonetheless be necessary to develop such specificity at the trial stage to ensure that life history requirements are met, and in the case of nationally listed species, legal requirements might also be considered. After the consideration of individual trial species, it will then be necessary to see how the use of IMMA criteria could protect multiple species collectively (Corrigan, 2013). 
The selection and management of protected areas requires some attention to threat (Williams et al., 2014). Vulnerability to disturbances is a feature of both EBSAs (criterion 4) and KBAs (criterion A); hence, the ultimate identification of IMMAs will require understanding of key threats to marine mammals. In general, these include entanglement in fishing gear, noise, hunting, water pollution, boat strikes, habitat loss, prey source reduction, and climate impacts (Polidoro et al., 2008). The degree to which any of these threats impacts specific species, particularly at different life-cycle stages, varies. Given the potential for synergistic effects of multiple threats leading to accelerated biodiversity loss and diminished ecosystem functioning, cumulative effects should be considered when possible (Brook et al., 2008; Darling and Cote, 2008; Halpern and Kappel, 2012).

\section{DISCUSSION: LEARNING FROM EBSAS AND KBAs}

Although differences in contexts, key actors, and histories have influenced the development of the EBSA and KBA criteria, both classification systems are grounded in sound science and global collaboration, and their application has been explored at regional and national levels. The overlap between EBSA and KBA criteria (e.g. EBSA Criterion 1 (Uniqueness or rarity) and KBA Criterion A (Threatened Biodiversity)) can be optimally utilized in the development of IMMA criteria. Some of the emerging common themes are described below.

\section{IMMAs and MPAs}

Although they have different objectives, both EBSA and KBA approaches have enabled the identification of multiple sites of global significance for biodiversity (International Union for Conservation of Nature (IUCN) and BirdLife International, 2013; Dunn et al., 2014). However, moving from identification to designation is a long and involved process. In the case of EBSAs, where significant progress has been made in hosting regional workshops resulting in candidate EBSAs, it is not yet clear to what extent these areas will become protected areas. It should not be assumed that all identified IMMAs will become MPAs - nor should they. There are a variety of management responses available. Unfortunately, some MPAs are failing to fully meet conservation objectives, and as identified by Edgar et al. (2014), there are at least five critical components of MPA design that play a role in the success of a given site. These five elements (and other factors like them) fall outside the scope of the KBA and EBSA criteria, but should come into play when narrowing down the choices for which sites to protect using spatial MPA-like measures.

\section{Scale}

Although both EBSAs and KBAs take a global perspective, it is at the regional and national levels where management decisions and actions are usually conducted. Deciding what constitutes 'key' or 'significant' is, in part, a question of scale. What is significant at a local scale may not be so at a regional or global scale. Similarly, what is identified as globally significant may cover a complete local area, and does not take into account the finer nuances and local subdivisions. To date, the EBSA workshops have been at a broad regional scale, and hence the EBSAs mostly reflect this perspective. However, the range in sizes and detail of delineation varies greatly. Current experience suggests that one size or scale will not 'fit all'.

KBA-like thresholds that relate to global populations may need to be re-evaluated at the regional and national scales. As part of the IMMA development process, it will be necessary to compile concrete examples of what 'importance' looks like for representative species, and subpopulations of these species where relevant, such as the Mediterranean short-beaked common dolphin (Delphinus delphis) where the regional Mediterranean population is listed as Endangered (EN) while the global status is listed as Least Concern (LC). Furthermore, regional distributions may vary because of historical anthropogenic pressures (such as whaling or pollution). Could areas that were once important to a species become so again? Will IMMAs only look at what is important to the current populations of animals, 
or could they also factor in the possibility of population recovery? These questions require consideration.

\section{Expert knowledge}

For EBSAs and KBAs alike, networks of professionals, government agencies, academia, and UN organizations have collaborated for several years, during which expert workshops played a central role. Expert workshops will likely also underpin the success of IMMA development. Tapping into the existing network from the EBSA and KBA processes would clearly reduce redundancies and link the Marine Mammal Protected Areas Task Force (MMPATF) and its partners to a wider global community. The EBSA and KBA processes can offer pointers on procedures, such as expert nominations, external review, and perhaps most importantly, how scientists became convinced of the need to engage in a process that many undoubtedly perceived as imperfect and lacking sufficient data. On this last point, it has been the observation of the authors that more data and information are often available than first thought. Individual studies can each feed into creating a coherent whole. For example, Williams et al. (2009) found that more than $6 \%$ of the resident killer whale population, listed as threatened by Canadian law, preferentially used a specific site (accounting for less than $1 \%$ of the range). When combined with additional studies considering different life-history stages, other species, and threats, a broader picture can emerge.

\section{Thresholds}

The complete absence of thresholds for the description of EBSAs has led to a broad set of potential sites which will require further sorting and refinement before appropriate management measures can be determined (Clark et al., 2014). The subjective approach of EBSAs to date has made some commentators uncomfortable, who point out that most of the ocean could potentially fit one or more of the EBSA criteria. While this fear may be true in principle, practice has not borne it out. Each regional workshop to date has successfully described a host of potential EBSAs, across a variety of locations and scales. Nevertheless, developing IMMA guidance for what constitutes 'important', and at what scale, will be necessary, and in those cases where data are available, thresholds could be a good approach.

As the latest iteration of KBA marine thresholds is still under development, it is hard to say how this will be applicable for the determination of IMMA thresholds. Given their parallel development, it is perhaps most likely that they will each help inform the other. The pros and cons of relative versus absolute thresholds have been discussed in the KBA context. Absolute thresholds were previously used; however, it appears that they will be replaced by relative thresholds based on percentages of actual or estimated populations. In the context of marine mammals, absolute numbers are only sometimes available, and hence relative values would likely be more applicable. However, considering the paucity of data existing across large portions of the marine environment, applying threshold-based criteria to the designation of IMMAs may not be possible for some marine mammal species, and for those with better data, it will still require exploration. A realistic process might involve application of the EBSA criteria tailored to marine mammal specificities and, pending a sufficient level of data availability, the application of KBA criteria and thresholds to determine where IMMAs could qualify as possible 'candidate KBAs' (Marine Mammal Protected Areas Task Force, 2014).

\section{Learning from the birds}

Now considered to fit under the KBA umbrella, IBAs were established before KBAs, through BirdLife International in 1981 (O'Dea et al., 2006; BirdLife International, 2014) and since have been well-received and adopted by the global community. This broad uptake and wide application provide useful guidance for developing IMMAs. IBAs account for about half of current KBA sites (Birdlife International, 2014) and the decades of experience that these areas provide have been invaluable to current conservation strategies. IBAs provide some pointers on what 
can be expected of site-based criteria like EBSAs and KBAs in meeting some of the needs of migratory species. While identifying 'stop-over' and destination sites important to migrating species is one consideration, another is the management of threats throughout the migratory corridors, which requires multi-lateral environmental agreements as well as monitoring and enforcement. KBAs and EBSAs, as place-based identifiers of significant areas needing management actions to sustain biodiversity features, will be limited in their capacity to meet all the life-history requirements of highly migratory marine mammal species. The successful nesting of global, regional, and national IBA criteria and designations suggests a way forward in developing IMMAs, which could likewise be tagged with differing levels of geographic significance.

The IBA process demonstrates the validity, efficiency, and effectiveness of having one institutionalized partnership overseeing management of the IBA database, communications, research, and outreach to partners as well as reviewing and designating or declaring new sites. That said, advancing the development of IMMAs with the broader support of IUCN, the CBD Secretariat, and the scientific, management and policy-development members of the marine mammal and marine conservation community will help ensure IMMAs have acceptance and mechanisms for adoption.

\section{Data variability, collation, and cooperation}

Strategies to address variations or gaps in data, such as modelling, have been explored in both EBSA and KBA processes and should inform IMMA development. Extensive effort is under way through the IUCN Marine Biodiversity Unit (MBU: www.sci.odu.edu/gmsa/) to improve coverage of marine data on the Red List, and some regions, such as the Eastern Central Pacific, are ideal locations to apply different suites of criteria to better understand how they overlap. The availability of comprehensive Red List Assessments of complete taxonomic clades (e.g. marine bony and cartilaginous fishes) at biogeographic scales provides an important precedent in what can be achieved through cooperative expert collaboration. Regarding Red List assessments, Bass et al., 2011 recommend testing thresholds first in areas with richer data for later comparison with those in data-poor locations. This kind of insight can be applied to IMMAs given regional variations in the quality of marine mammal data. Furthermore, global initiatives such as the MBU and OBIS SEAMAP, a database hosting and making available an increasing number of marine mammal datasets (Halpin et al., 2006), is likely to significantly improve the task of sharing and taking advantage of existing marine mammal ecological data, as well as for other marine taxa.

\section{Dynamic management}

One advantage in using global classification criteria is that they help categorize the vast expanse of the ocean into manageable spaces for defining further action/management. Although EBSAs are intentionally broad in their intent, and KBAs are arguably more focused, both create boundaries within which additional management and research actions can be determined. However, the boundaries themselves may be difficult to justify, particularly in a fluid environment where seasonal variations are coupled with a changing climate. The open ocean poses a challenge to those approaches that assume static boundaries typically used for nearshore or terrestrial protected areas. In the pelagic realm frequented by cetaceans, it is likely that at least in some instances site-based conservation approaches are not going to be sufficient, or even suitable. However, IMMAs, being a new development, provide an opportunity to explore how static notions of MPAs can merge with more flexible modern management interventions, supporting 'dynamic ocean management' (Game et al., 2009; Hobday et al., 2014). Various data streams, such as from tracking and remote sensing technologies, could conceivably be fused together to support near real-time decision-making on where a given IMMA is and in which direction it is headed.

The development of IMMAs could thereby draw upon, and advance, existing global processes. Based on the success of IBAs, there is certainly optimism for what a species-focused approach, such as 
IMMAs, could in the future achieve. However, when compared with seabird data, this optimism is tempered with the sobering reality that marine mammal data, though better than for many other marine species, are still patchy, inconsistently collected, and not yet aggregated into a global repository (such as the Seabird Tracking Database: www.seabirdtracking.org). There is still some distance to go before dynamic IMMAs would be so accessible.

\section{Integrating EBSAs, KBAs, and IMMAs}

It is anticipated that IMMAs would nest fully within what would constitute an EBSA, and either fully or at least to a large degree within KBAs - acknowledging that those thresholds are still under development. However, in practice, it is likely that given regional/local knowledge and expertise, many IMMAs could be identified before being officially recognized by either one of these global designations. In the end, though, IMMAs, KBAs, and EBSAs should be seen as complementary and mutually supportive. Through the systematic analysis of global and regional datasets and through the application of quantitative criteria and thresholds that are transparent and repeatable, new sites that contribute significantly to the global persistence of marine mammal biodiversity will likely be identified by all three. On the contrary, without IMMAs, some places important to marine mammals would likely be overlooked by these generalized global criteria systems. The development of IMMA criteria, therefore, remains pertinent and timely. The challenges ahead, as outlined in this paper, are formidable but not insurmountable.

\section{ACKNOWLEDGEMENTS}

Appreciation is extended to the 19 experts who participated in the 2013 MMPATF workshop in Marseilles, France. Their dedication and contributions provided rich dialogue and subsequent discussions that informed this paper. Several organizations provided financial and logistical support for the workshop, including Animal Welfare Institute, The Pacific Life Foundation, The Ocean Foundation, Whale and
Dolphin Conservation, and the Network of Marine Protected Area Managers in the Mediterranean (MedPAN). Annabelle Cuttelod provided support in early stages of the paper and Penny Langhammer contributed suggestions that substantially improved and clarified the KBA and overall content. Lastly, helpful insights were offered by Hugh Possingham and Jennifer McGowan at the University of Queensland.

\section{REFERENCES}

Abdul Malak D, Livingstone SR, Pollard D, Polidoro BA, Cuttelod A, Bariche M, Bilecenoglu M, Carpenter KE, Collette BB, Francour P, et al. 2011. Overview of the conservation status of the marine fishes of the Mediterranean Sea, IUCN: Gland, Switzerland and Malaga, Spain.

Agardy T, Notarbartolo di Sciara G, Christie P. 2011. Mind the gap: addressing the shortcomings of marine protected areas through large scale marine spatial planning. Marine Policy 35: 226-232.

Ambal RGR, Duya MV, Cruz MA, Coroza OG, Vergara SG, De Silva N, Molinyawe N, Tabaranza B. 2012. Key Biodiversity areas in the Philippines: priorities for conservation. Journal of Threatened Taxa 4: 2788-2796.

Anderson S. 2002. Identifying Important Plant Areas. Plantlife International: London, UK.

Ardron J, Dunn DC, Corrigan C, Gjerde K, Halpin P, Rice J, Vanden Berghe E, Vierros M. 2009. Defining ecologically or biologically significant areas in the open oceans and deep seas: analysis, tools, resources and illustrations. https://www.cbd.int/doc/meetings/mar/ ewbcsima-01/other/ewbcsima-01-multiorgs-en.pdf/ (17 February 2014).

Australia Government Department of Environment. 2014. http://www.environment.gov.au/cgi-bin/sprat/public/ publicspecies.pl?taxon_id=38\#threats. (28 March 2014).

Bass D, Anderson P, De Silva N. 2011. Applying thresholds to identify key biodiversity areas for marine turtles in Melanesia. Animal Conservation 14: 1-11.

BirdLife International. 2014. http://www.birdlife.org/ worldwide/programmes/important-bird-and-biodiversityareas-ibas (27 March 2014 and 9 April 2014).

Bland LM, Collen B, Orme CDL, Bielby J. 2012. Data uncertainty and the selectivity of extinction risk in freshwater invertebrates. Diversity and Distributions 18: 1211-1220.

Brettell L. 2013. Department of Sustainability, Environment, Water, Population and Communities, Australia. Personal communication, 14 September 2013.

Brook BW, Sodhi NS, Bradshaw CJA. 2008. Synergies among extinction drivers under global change. Trends in Ecology and Evolution 23: 453-460.

Butchart SHM, Scharlemann JPW, Evans MI, Quader S, Aricò $\mathrm{S}$, Arinaitwe J, Balman M, Bennun LA, Bertzky B, Besançon C, et al. 2012. Protecting important sites for biodiversity contributes to meeting global conservation targets. PLoS ONE 7: e32529. 
CBD. 2005. Report of the Scientific Experts' Workshop on Criteria for Identifying Ecologically or Biologically Significant Areas Beyond National Jurisdiction. 6-8 December 2005, Ottawa, Canada. UNEP/CBD/COP/8/ INF/39.

CBD. 2008. http://www.cbd.int/decisions/cop/?m=cop-09/ (27 March 2014).

CBD. 2010. Report of the Tenth Meeting of the Conference of the Parties to the Convention on Biological Diversity. Convention on Biological Diversity. http://www.cbd.int/ doc/meetings/cop/cop-10/official/cop-10-27-en.pdf/ (12 March 2014).

CetMap. 2014. http://cetsound.noaa.gov/index.html/ (28 March 2014). http://www.st.nmfs.noaa.gov/cetsound/ cetacean.html (accessed 21 May 2014).

Clark MR, Rowden AA, Schlacher TA, Guinotte J, Dunstan PK, Williams A, O'Hara TD, Watling L, Niklitschek E, Tsuchida S. 2014. Identifying ecologically or biologically significant areas (EBSA): a systematic method and its application to seamounts in the South Pacific Ocean. Ocean and Coastal Management 91: 65-79.

Committee on Taxonomy. 2014. www.marinemammalscience. org/ (25 March 2014).

Corrigan C. 2013. Options for the development of criteria to identify the Important Marine Mammal Areas (IMMAs). IUCN Joint Marine Mammal Protected Area Task Force. MMPATF Working paper 1.

Darling ES, Cote IM. 2008. Quantifying the evidence for ecological synergies. Ecology Letters 11: 1278-1286.

Darwall W, Vie J-C. 2005. Identifying important sites for conservation of freshwater biodiversity: extending the species-based approach. Fisheries Management and Ecology 12: 287-293.

Dearden P, Topelko KN. 2005. Establishing criteria for the identification of ecologically and biologically significant areas on the high seas. Marine Protected Areas Research Group: Victoria, British Columbia.

Department of the Environment and Heritage. 2005. http:// www.environment.gov.au/resource/humpback-whalerecovery-plan-2005-2010 (24 March 2014).

Dulvy NK. 2013. Super-size MPAs and the marginalization of species conservation. Aquatic Conservation: Marine and Freshwater Ecosystems 23: 357-362.

Dunn DC, Ardron J, Bax N, Bernal P, Cleary J, Cresswell I, Donnelly B, Dunstan P, Gjerde K, Johnson D, et al. 2014. The convention on biological diversity's ecologically or biologically significant areas: origins, development, and current status. Marine Policy. DOI: 10.1016/j. marpol.2013.12.002i

Edgar GJ, Brooks TM. 2011. Testing absolute and percentage thresholds in the identification of key biodiversity areas. Animal Conservation 14: 12-13.

Edgar GJ, Banks S, Bensted-Smith R, Calvopiña M, Chiriboga A, Garske LE, Henderson S, Miller KA, Salazar S. 2008a. Conservation of threatened species in the Galapagos Marine Reserve through identification and protection of marine key biodiversity areas. Aquatic Conservation: Marine and Freshwater Ecosystems 18: 955-968.

Edgar GJ, Langhammer PF, Allen G, Brooks TM, Brodie J, Crosse W, De Silva N, Fishpool LDC, Foster MN, Knox $\mathrm{DH}$, et al. 2008b. Key biodiversity areas as globally significant target sites for the conservation of marine biological diversity. Aquatic Conservation: Marine and Freshwater Ecosystems 18: 969-983.

Edgar GJ, Stuart-Smith RD, Willis TJ, Kininmonth S, Baker SC, Banks S, Barrett NS, Becerro MA, Bernard ATF, Berkhout J, et al. 2014. Global conservation outcomes depend on marine protected areas with five key features. Nature 506: 216-220.

Eken G, Bennun L, Brooks TM, Darwall W, Fishpool LDC, Foster M, Knox D, Langhammer P, Matiku P, Radford E, et al. 2004. Key biodiversity areas as site conservation targets. BioScience 54: 1110-1118.

Farr M, Stoeckl N, Alam Beg R. 2014. The non-consumptive (tourism) 'value' of marine species in the Northern section of the Great Barrier Reef. Marine Policy 43: 89-103.

Food and Agriculture Organization of the United Nations F. 2009. http://www.fao.org/docrep/011/i0816t/i0816t00. htm (24 March 2014).

Foster MN, Brooks TM, Cuttelod A, De Silva N, Fishpool LDC, Radford EA, Woodley S. 2012. The identification of site of biodiversity conservation significance: progress with the application of a global standard. Journal of Threatened Taxa 4: 2733-2744.

Game ET, Grantham HS, Hobday AJ, Pressey RL, Lombard AT, Beckley LE, Gjerde K, Bustamante R, Possingham HP, Richardson AJ. 2009. Pelagic protected areas: the missing dimension in ocean conservation. Trends in Ecology and Evolution 24: 360-369.

Gomez-Salazara C, Colla M, Whitehead H. 2012. River dolphins as indicators of ecosystem degradation in large tropical rivers. Ecological Indicators 23: 19-26.

Halpern BS, Kappel CV. 2012. Extinction risk in a changing ocean. In Saving a Milion Species: Extinction Risk from Climate Change, Hannan L (ed.). Island Press: Washington, DC; 285-307.

Halpin PN, Read AJ, Best BD, Hyrenbach KD, Fujioka E, Coyne MS, Crowder LB, Freeman SA, Spoerri C. 2006. OBIS-SEAMAP: developing a biogeographic research data commons for the ecological studies of marine mammals, seabirds, and sea turtles. Marine Ecology Progress Series 316: 239-246.

Hobday AJ, Maxwell SM, Forgie J, McDonald J, Darby M, Seto K, Bailey H, Bograd SJ, Briscoe DK, Costa DP, et al. 2014. Dynamic ocean management: integrating scientific and technological capacity with law, policy and management. Stanford Environmental Law Journal 33: 125-165.

Holland RA, Darwall WRT, Smith KG. 2012. Conservation priorities for freshwater biodiversity: the Key Biodiversity Area approach refined and tested for continental Africa. Biological Conservation 148: 167-179.

Hoyt E. 2011. Marine Protected Areas for Whales, Dolphins and Porpoises: a World Handbook for Cetacean Habitat Conservation and Planning. Earthscan/Taylor \& Francis: New York and London.

International Maritime Organization. 2005. http://www.imo. org/OurWork/Environment/PollutionPrevention/PSSAs/ Pages/Default.aspx (26 March 2014).

IUCN. 2001. http://www.redlist.org/info/categories_ criteria2001.html (7 September 2009).

IUCN. 2012. Consolidating the standards for identifying sites that contribute significantly to the global persistence of biodiversity: the results of a framing workshop. International Union for Conservation of Nature. Gland, Switzerland. 
IUCN. 2013. Identifying sites that contribute significantly to the global persistence of biodiversity (Key Biodiversity Areas): criteria and delineation technical workshop report. International Union for Conservation of Nature. Gland, Switzerland.

IUCN and BirdLife International. 2013. Key Biodiversity Areas: identifying areas of particular importance for biodiversity in support of the Aichi Targets. Convention on Biological Diversity Subsidiary Body on Scientific, Technical and Technological Advice.

Kareiva P, Marvier M. 2003. Conserving biodiversity coldspots. American Scientist 91: 344-351.

Kennedy AS, Zerbini AN, Vásquez OV, Gandilhon N, Clapham PJ, Adam O. 2013. Local and migratory movements of humpback whales (Megaptera novaeangliae) satellite-tracked in the North Atlantic Ocean. Canadian Journal of Zoology 92: 9-18.

Langhammer PF, Bakarr MI, Bennun LA, Brooks TM, Clay RP, Darwall W, De Silva N, Edgar GJ, Eken G, Fishpool LDC, et al. 2007. Identification and gap analysis of Key Biodiversity Areas: targets for comprehensive protected area systems. IUCN: Gland, Switzerland.

Linzey AV. 2002. Important Mammal Areas: a US pilot project. In Society for Conservation Biology. 16th Annual Meeting: Programme and Abstracts, Canterbury, UK. Durrell Institute of Conservation and Ecology.

Lotze HK, Coll M, Magera AM, Ward-Paige C, Airoldi L. 2011. Recovery of marine animal populations and ecosystems. Trends in Ecology and Evolution 26: 595-605.

Margules CR, Pressey RL. 2000. Systematic conservation planning. Nature 405: 243-253.

Marine Mammal Protected Areas Task Force I. 2014. Report of the workshop for the development of Important Marine Mammal Area (IMMA) Criteria. Marseille, France, 22 October 2013. IUCN SSC-WCPA.

McIntosh N. 1999. http://www.umich.edu/ esupdate/ library/99.7-8/mcintosh.html (28 March 2014).

Morais AR, Siqueira MN, Lemes P, Maciel NM, De Marco Jr P, Brito D. 2013. Unraveling the conservation status of Data Deficient species. Biological Conservation 166: 98-102.

O’Dea N, Araújo MB, Whittaker RJ. 2006. How well do Important Bird Areas represent species and minimize conservation conflict in the tropical Andes? Diversity and Distributions 12: 205-214.

Plantlife International. 2004. Identifying and protecting the world's most Important Plant Areas: A guide to implementing Target 5 of the Global Strategy for Plant Conservation. Plantlife International: Salisbury, UK.
Polidoro BA, Livingstone SR, Carpenter KE, Hutchinson B, Mast RB, Pilcher N, Sadovy de Mitcheson Y, Valenti S. 2008. Status of the world's marine species. In The 2008 Review of the IUCN Red List of Threatened Species, Vie J-C, Hilton-Taylor C, Stuart SN (eds). IUCN: Gland, Switzerland.

Polidoro BA, Brooks TM, Carpenter KE, Edgar GJ, Henderson S, Sanciangco J, Robertson DR. 2012. Patterns of extinction risk and threat for marine vertebrates and habitat-forming species in the Tropical Eastern Pacific. Marine Ecology Progress Series 448: 93-104.

Pressey RL, Taffs KH. 2001. Scheduling conservation action in production landscapes: priority areas in western New South Wales defined by irreplaceability and vulnerability to vegetation loss. Biological Conservation 100: 355-376.

Ramsar. 1999. Strategic Framework and guidelines for the future development of the List of Wetlands of International Importance of the Convention on Wetlands (Ramsar, Iran, 1971). Third edition, as adopted by Resolution VII.11 (COP7, 1999) and amended by Resolutions VII.13 (1999), VIII.11 and VIII.33 (COP8, 2002), IX.1 Annexes A and B (COP9, 2005), and X.20 (COP10, 2008).

Reeves R, Notarbartolo di Sciara G. compilers and editors. 2006. The Status and Distribution of Cetaceans in the Black Sea and Mediterranean Sea. IUCN Centre for Mediterranean Cooperation: Malaga, Spain.

Rochette J, Gjerde K, Druel E, Ardron J, Craw A, Halpin P, Pendleton L, Teleki K, Cleary J. 2014. Delivering the Aichi target 11: challenges and opportunities for marine areas beyond national jurisdiction. Aquatic Conservation: Marine and Freshwater Ecosystems: this issue.

van Swaay CAM, Warren MS. 2003. Prime Butterfly Areas in Europe: pPriority sites for conservation. National Reference Center for Agriculture, Nature and Fisheries, Ministry of Agriculture, Nature Management and Fisheries.

Weaver P, Johnson D. 2012. Biodiversity: think big for marine conservation. Nature 483: 399.

Williams R, Lusseau D, Hammond P. 2009. The role of social aggregations and protected areas in killer whale conservation: the mixed blessing of critical habitat. Biological Conservation 142: 709-719.

Williams R, Grand J, Hooker SK, Buckland ST, Reeves RR, Rojas-Bracho L, Sandilands D, Kaschner KR. 2014. Prioritizing global marine mammal habitats using density maps in place of range maps. Ecography 37: 212-220.

World Heritage Center W. 1975. http://portal.unesco.org/en/ ev.php-URL_ID=13055\&URL_DO=DO_TOPIC\&URL_ SECTION=201.html (28 March 2014). 